\title{
Registration of myometrial activity using multiple site electromyography in cyclic mares
}

\author{
M. H. T. Troedsson ${ }^{1}$, A. O. G. Wiström ${ }^{2}$, I. K. M. Liu ${ }^{1}$, M. Ing $^{1}$, \\ J. Pascoe ${ }^{3}$ and M. Thurmond ${ }^{4}$ \\ ${ }^{1}$ Department of Reproduction, ${ }^{3}$ Department of Surgery, ${ }^{4}$ Department of Epidemiology and Preventive \\ Medicine, School of Veterinary Medicine; and ${ }^{2}$ Department of Civil Engineering, University of \\ California, Davis, CA 95616, USA
}

\begin{abstract}
A method for interpreting and analysing electromyographic (EMG) data of myometrial electrical activity was established. This method was used to study EMG activity in the uterus during the various stages of the oestrous cycle in mares. Recordings were analysed from four pairs of electrodes that were surgically implanted in the myometrium of four reproductively sound mares. The electrodes were placed at the tip, middle and base of the left horn and in the uterine body. Electrical activity was monitored by a polygraph. Data were transformed to a digitized form and statistically analysed. Myometrial electrical activity during oestrus and dioestrus was analysed for frequency (number of activity bursts per hour), duration (time elapsed from the start to the end of a burst) and intensity (peaks per minute). In addition, the degrees of synchronous activity among all of the monitored sites of the uterus were compared. The minimal amount of time of EMG recordings that allowed meaningful statistical analyses was determined to be $3.5 \mathrm{~h}$ during oestrus and $7 \mathrm{~h}$ during dioestrus. Variations in intensity of electrical activity were seen between the sites of implanted electrodes $(P<0.001)$. Electrical activity was highest in the middle of the horn and lowest in the uterine body. The frequency of activity bursts was the same during oestrus and dioestrus $(4.35 \pm 0.22$ and $4.44 \pm 0.20$, respectively). The duration and intensity of uterine electrical activity depended on the stage of the oestrous cycle. The mean duration of uterine activity bursts during dioestrus was significantly $(P<0.005)$ shorter during oestrus $(3.32 \pm 0.18 \mathrm{~min})$ than during dioestrus $(5.7 \pm 0.39 \mathrm{~min})$. The intensity of bursts was higher during oestrus than during dioestrus $(P<0.005)$. In contrast, the total time of uterine activity was higher during dioestrus than during oestrus $(P<0.005)$. Synchronization of uterine electrical activity among different sites of the uterus was more marked during oestrus than during dioestrus $(P<0.005)$. It was suggested that a hormone-dependent mechanism for the regulation of cell communication is responsible for at least part of the changes of myometrial electrical activity that was observed at different stages of the oestrous cycle. It was concluded from the study that the method described for analysing EMG data allowed for an objective and repeatable interpretation of myometrial electrical activity.
\end{abstract}

\section{Introduction}

The electromyographic (EMG) activity of the uterus during the oestrous cycle has been described in several domestic species (Zerobin and Spörri, 1972; Naaktgeboren et al., 1973; Rousseau and Prud'homme, 1974; Ruckebush and Bayard, 1975; Taverne et al., 1979a; Krishnamurti et al., 1982; Toutaine et al., 1983; Thorburn et al., 1984; Faltsi and Brikas, 1990). Taverne et al. (1979b) used EMG recordings to describe uterine activity in the cyclic mare. They found differences in myometrial electrical activity during different stages of the oestrous cycle. The observed electromyographic activity of the uterus of mares

Received 24 August 1992 differed, however, from similar recordings of the oestrous cycle in other species. Studies of uterine activity using intrauterine pressure devices have not supported the results of Taverne and co-workers (Goddard et al., 1985; Ko et al., 1989).

Electromyographic data is often presented in terms of EMG recordings. General interpretations are based on subjective visual impressions of monitored electrical patterns. The interpretation of several hours of EMG recordings is based solely on a figure that shows a small proportion of the data. An objective method for interpretation of EMG data is necessary to perform statistical analyses; this would include translation of specified parameters from EMG recordings into a digital code.

The purpose of the present study was: (1) to develop an objective method for analysis and interpretation of EMG data 
and (2) to use this method to study electromyographic activity in the uterus during the various siages of the oestrous cycle in mares.

\section{Materials and Methods}

\section{Mares}

Four healthy mares (3-5 years of age) were used in this study. They were all confirmed to be normally cyclic and had no history of fertility problems. The mares were fed alfalfa hay and were kept in stalls. During the recordings, the mares were allowed to move freely in a tiestall with the wires from the electrodes attached to the ceiling via a suspensory band. Some of the recordings were carried out with the mare confined to an examination stock. The stage of the oestrous cycle was determined by transrectal ultrasonographic examinations of the reproductive tract every other day for detection of ovarian follicles and the presence of a corpus luteum, and also by teasing the mares with a stallion. Oestrus and dioestrus were confirmed by determining concentrations of progesterone in blood samples obtained at each recording session.

\section{Collection of blood samples}

In conjunction with each recording session, $10 \mathrm{ml}$ of venous blood was withdrawn from the jugular vein in a vacutainer system (Becton Dickinson, Rutherford, NJ) containing sodium heparin as an anticoagulant. The samples were centrifuged at $400 \mathrm{~g}$ for $10 \mathrm{~min}$ and plasma was removed and stored at $-20^{\circ} \mathrm{C}$ until analysed for progesterone.

\section{Hormone analysis}

Plasma progesterone concentration was determined using a solid-phase microtitre plate enzymeimmunoassay as described by Munro and Stabenfeldt (1984). Progesterone 3-O-carboxymethyloxime-horseradish peroxidase was used as the label and antiserum from rabbits was raised against a progesterone $11 \alpha$-hemisuccinyl-BSA immunogen. Progesterone 3-O-carbomethyloxime and $11 \alpha$-hemisuccinate-BSA were purchased from Steraloids, Inc. (Wilton, New Hampshire). Horseradish peroxidase was obtained from Sigma Chemical Co. (St Louis, MO). The mean intra-assay coefficient of variation was $9.97 \%$ and the average interassay coefficients of variation for pools of high, medium and low progesterone concentration were $4.9,6.2$ and $10.5 \%$, respectively. The sensitivity of the progesterone assay was $<0.1 \mathrm{ng} \mathrm{ml}^{-1}$.

\section{Myometrial electrode implantation}

Six pairs of bipolar electrodes were surgically implanted in the myometrium of each mare. The uterus was exposed via a midventral laparotomy performed under general anaesthesia induced by $100 \mathrm{mg}$ guaifenesin $\mathrm{kg}^{-1}$ (Rhone-Poulene, Collegeville, PA) and $2 \mathrm{mg}$ thiamylal kg ${ }^{-1}$ (Surital; Parke-Davis, Morris Plains, NJ) i.v. and maintained with halothane (Halocarbon Laboratories, N. Augusta, SC). Three pairs of electrodes (44-gauge multistrand stainless steel Teflon coated wire) were implanted into the myometrium of the left uterine horn, spread 3-5 cm apart at the tip of the horn, the middle of the horn, the base of the horn and the uterine body. Similarly, two pairs of electrodes were implanted at the mid-section and base of the right horn. A loop was made in each wire $5 \mathrm{~cm}$ from the distal end of the electrodes. The Teflon was stripped from the electrodes over a $10 \mathrm{~mm}$ long segment distal to the loop. Pairs of electrodes were implanted into the myometrium, using a tapered needle, and secured via a suture (prolene 3-0) through the loop. Electrodes within a pair were implanted approximately $1 \mathrm{~cm}$ apart. The most distal end of the electrodes was cut, leaving the stripped area embedded in the myometrium. This technique allowed exposure of the electrodes to both the longitudinal and circular layers of the myometrium. The recorded activity therefore represented the combined activity of the two myometrial layers. Each electrode, covered by a Teflon tube, was passed through the abdominal wall of the left flank, tunnelled s.c., exteriorized near the withers, fixed in place and capped.

\section{$E M G$ recordings}

After implantation and recovery from surgery, the mares were allowed to rest for at least one week to allow the uterus to stabilize. Electrical activity (EMG), was monitored by a Grass polygraph with each electrode joined to the appropriate lead of the polygraph. EMG signals were amplified through Grass DC preamplifiers and the signals were transcribed to a Grass polygraph at a chart speed of $10 \mathrm{~mm} \mathrm{~min}{ }^{-1}$ and at an amplitude of $50 \mu \mathrm{V} \mathrm{cm}^{-1}$. Signal filters were set at 10 and $35 \mathrm{~Hz}$ (Haluska et al., 1987).

Recordings were carried out during oestrus and dioestrus. Each recording session lasted for a minimum of $6 \mathrm{~h}$ and maximum of $15 \mathrm{~h}$. At the end of each recording, 20 iu oxytocin was administered i.v. as a control for myometrial activity. Although the effect of oxytocin on electrical myometrial activity demonstrated a different pattern during oestrus and dioestrus, the response was marked at all stages of the cycle. The administration of oxytocin was therefore considered to be an accurate positive control for electrical myometrial activity.

\section{Analyses}

All recordings were manually transformed to a digitized form and myometrial electrical activity was analysed in three ways. First, frequency was defined as the number of activity bursts per hour. A burst was defined as electrical activity consisting of at least ten recorded peaks per minute and separated from other bursts by at least 1 min (Fig. 1). Second, duration was defined as the time (minutes) elapsed from the start to the end of a burst. Third, intensity was measured as the number of spikes per minute (Fig. 2). Intensity was coded as $0=$ quiescence $(<10$ spikes $\left.\min ^{-1}\right), \quad 1=$ low $\left(11-15\right.$ spikes $\left.\min ^{-1}\right), 2=$ intermediate $\left(16-20\right.$ spikes $\left.\min ^{-1}\right)$, or $3=$ high $\left(>20\right.$ spikes $\min ^{-1}$ ). The degree of intensity was calculated as the degree $(1-3)$ of all registered electrical activity divided by the total duration of activity bursts. In addition, total intensity was analysed as the degree of registered electrical activity, including periods of quiescence, divided by the total time of registration. Total 


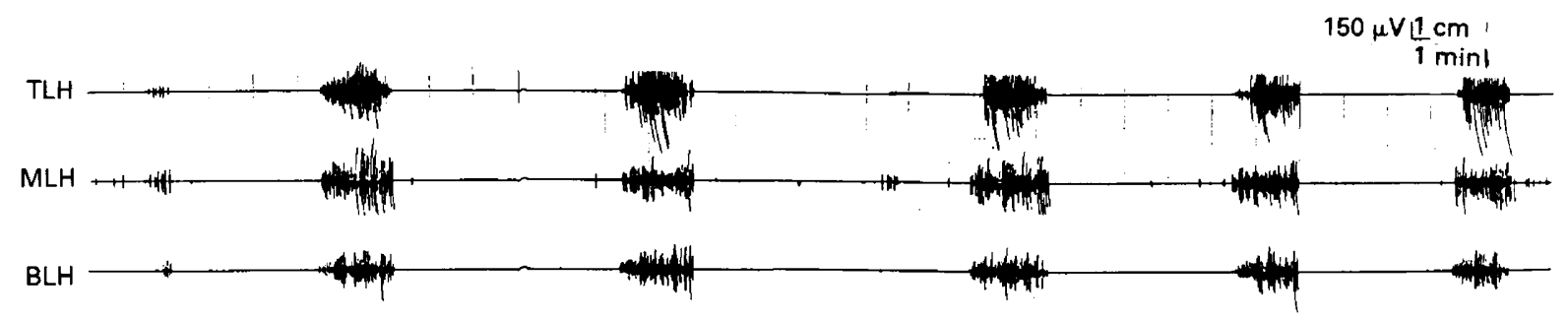

UB $\mathbf{t}$

a

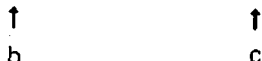

Fig. 1. Electromyographic (EMG) recordings of myometrial electrical activity during $1.5 \mathrm{~h}$ from a mare in oestrus. Recordings were made from the tip of the left horn (TLH), middle of the left hom (MLH), base of the left hom (BLH) and the uterine body (UB). A uterine burst was defined as electrical activity consisting of $>10$ recorded spikes separated from other bursts by at least 1 min. Most bursts have a duration of $4-5 \mathrm{~min}$. The frequency of activity bursts was defined as the number of bursts $\mathrm{h}^{-1}$. Synchrony was expressed as the number of electrode sites which were active simultaneously and the number which were quiescent simultaneously. a and c: intermediate synchronous activity ( 3 active sites and 1 quiescent site (a) or 3 quiescent sites and 1 active site (c)); b: complete synchrony ( 4 active sites and no quiescence).

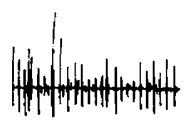

1

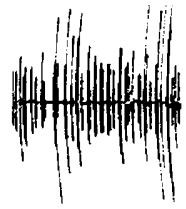

2

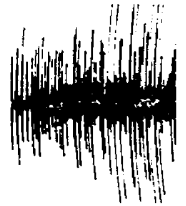

3

Fig. 2. Electromyographic (EMG) recordings with three different examples of intensity. Each sample represents $2.5 \mathrm{~min}$ of electrical activity. The intensity of myometrial electrical activity was calculated from the number of recorded spikes $\min ^{-1}$. 1: low intensity (11-15 spikes $\left.\min ^{-1}\right) ; 2$ : intermediate intensity $\left(16-20\right.$ spikes $\left.\min ^{-1}\right)$; and 3: high intensity $\left(>20\right.$ spikes $\left.\min ^{-1}\right)$.

intensity was graded from 0 to 3 . All registered electrical activity, regardless of intensity, was classified as total uterine activity and was expressed as the percentage of time any electrical activity was recorded.

In addition, the presence or absence of synchronous activity was expressed as the number of implantation sites that were active simultaneously and the number which were quiescent simultaneously (Fig. 1). Complete synchronous activity occurred when there was simultaneous activity $(4,0)$ or quiescence $(0,4)$ at all locations. Intermediate synchronous activity occurred when there was simultaneous activity $(3,1)$ or quiescence $(1,3)$ at three locations. Absence of synchronous activity occurred when simultaneous activity occurred at two sites $(2,2)$.

\section{Statistical analyses}

To determine the minimal amount of time of EMG recordings that allowed for meaningful statistical analyses, recordings were monitored and plotted until stabilization of means and standard deviations occurred.

The means of the degree of intensity during electrical activity as well as the total intensity were analysed for statistical differences between sites of the uterus using a one-way analysis of variance (ANOVA) with repeated measures. Tukey's HSD test was used to detect significant differences between individual pairs of means.

The incidence of various durations of uterine electrical activity and the proportion of synchronization were tested for significant differences during oestrus and dioestrus using a $\chi^{2}$ test. In addition, the means of burst durations were tested for significant differences between oestrus and dioestrus, using a $t$ test for populations with unequal variances. A Student's $t$ test was also used to test for mean differences in frequency of activity bursts, intensity and total uterine electrical activity during oestrus and dioestrus. Because of technical problems with the two pairs of electrodes implanted in the right horn of one mare, whereby the mare destroyed the exteriorization of this set of wires, data from the right horn was excluded from all mares and analyses were made only from the four pairs of electrodes in the left horn and uterine body.

The results were expressed as means \pm SEM. Significance was set at $P<0.05$.

\section{Results}

Mean concentrations of progesterone in plasma of mares recorded during oestrus were $0.16 \mathrm{ng} \mathrm{ml}^{-1}$ (range $=0.03-0.4$ ), and during dioestrus averaged $5.2 \mathrm{ng} \mathrm{ml}^{-1}$ with a range of 2.2-11.7.

A recording time of $3.5 \mathrm{~h}$ during oestrus gave enough data for a reliable analysis, but dioestrous mares had to be monitored for more than $7 \mathrm{~h}$ before stabilization of the data was seen (Figs 3 and 4 ).

\section{$E M G$ recordings at different sites of the uterus}

Significant differences in intensity during bursts of activity were observed during dioestrus between different parts of the uterus $(P<0.001)$ (Table I). More high intensity bursts were recorded at the middle and base of the horn than at the tip of the horn and the uterine body. These differences were not found during oestrus, at which time equal intensity was observed at all sites of the myometrium monitored $(P>0.1)$.

Variations in total intensity between the sites of implanted electrodes were observed throughout the oestrous cycle 

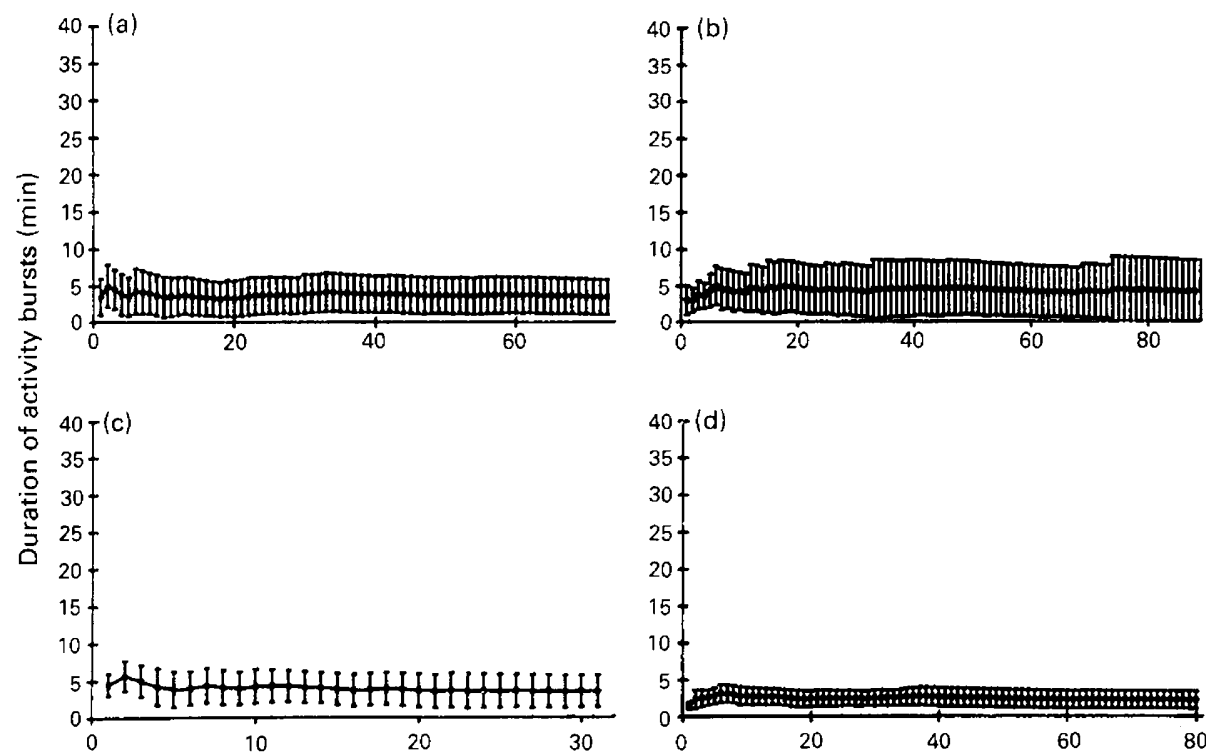

Number of activity bursts

Fig. 3. The mean duration of activity bursts during oestrus at four different sites of the uterus of mares. (a) Tip of the left uterine horn; (b) middle of the left uterine horn; (c) base of the left uterine horn; and (d) uterine body. A period of $2-3.5 \mathrm{~h}$ was required before stabilization of the mean and SD of activity burst duration. Data are expressed as mean \pm SD.

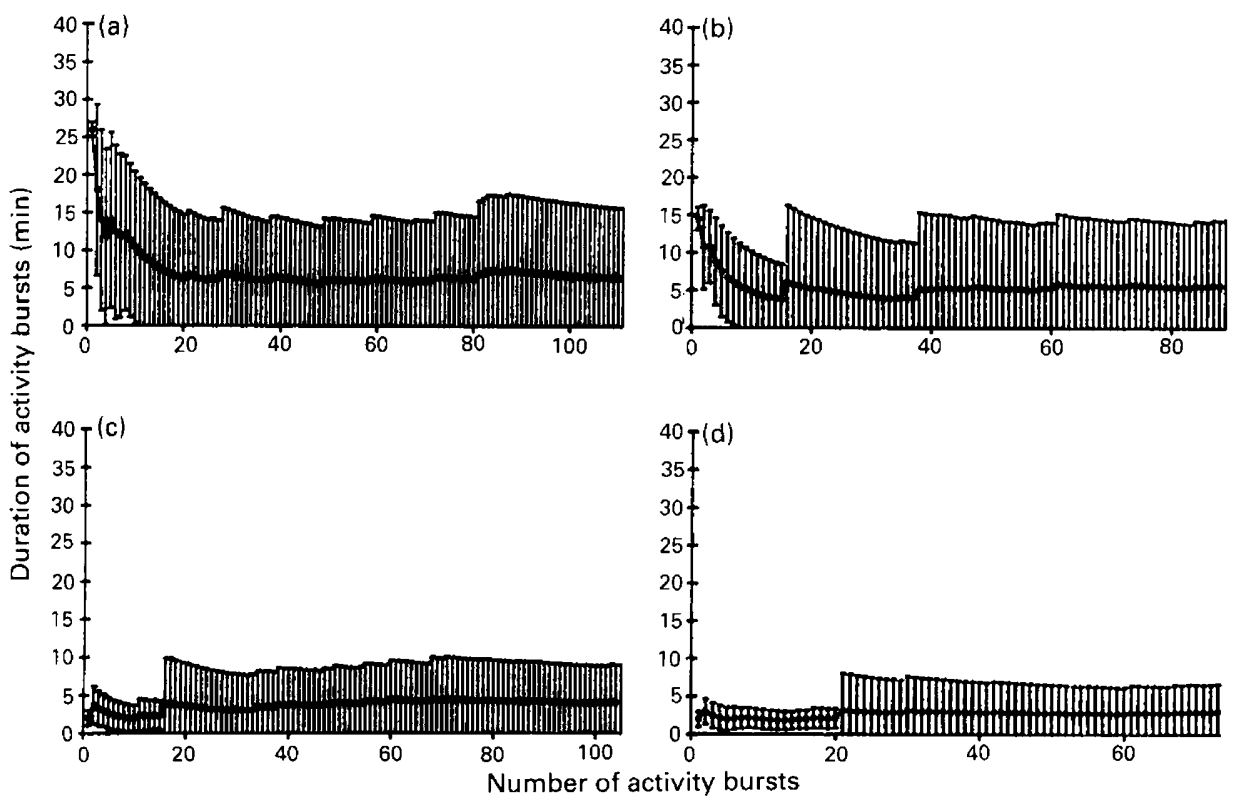

Fig. 4. The mean duration of activity bursts during dioestrus at four different sites of the uterus of mares. (a) Tip of the left uterine horn; (b) middle of the left uterine horn; (c) base of the left uterine horn; and (d) uterine body. A period of $>8 \mathrm{~h}$ was required before stabilization of the mean and SD of activity burst duration. Data are expressed as means \pm SD.

$(P<0.001)$. During oestrus and dioestrus, the total uterine electrical activity was highest in the middle of the horn. In addition, the total activity in the uterine body during dioestrus was significantly lower than in other sections of the uterus. A similar pattern of marked uterine activity in the middle of the uterine horn was also seen for total uterine activity, frequency and duration of electrical activity.

\section{Myometrial electrical activity during oestrus and dioestrus}

Frequency. The frequency of activity bursts was similar during oestrus and dioestrus with a mean of $4.35 \pm 0.22 \mathrm{~h}^{-1}$ during oestrus and $4.44 \pm 0.20 \mathrm{~h}^{-1}$ during dioestrus $(P>0.1)$.

Duration. Significant differences in durations of the burst were seen during the oestrous cycle $(P<0.005)$. Although 
Table 1. The degree of intensity and total intensity of myometrial electrical activity at different sites in the uterus during oestrus and dioestrus in mares

\begin{tabular}{lcccc}
\hline Parameter & TH & MH & BH & UB \\
\hline $\begin{array}{l}\text { Oestrus } \\
\text { Degree of intensity } \\
\quad(\text { mean } \pm \text { SEM) }(1-3)\end{array}$ & $2.03 \pm 0.06^{\mathrm{a}}$ & $2.10 \pm 0.04^{\mathrm{a}}$ & $2.12 \pm 0.07^{\mathrm{a}}$ & $1.93 \pm 0.06^{\mathrm{a}}$ \\
$\begin{array}{c}\text { Total intensity } \\
(\text { mean } \pm \text { SEM) }(0-3)\end{array}$ & $0.46 \pm 0.04^{\mathrm{a}}$ & $0.86 \pm 0.05^{\mathrm{b}}$ & $0.49 \pm 0.05^{\mathrm{a}}$ & $0.37 \pm 0.04^{\mathrm{a}}$ \\
$\begin{array}{c}\text { Dioestrus } \\
\text { Degree of intensity } \\
(\text { mean } \pm \text { SEM) }(1-3)\end{array}$ & $1.57 \pm 0.03^{\mathrm{c}}$ & $1.73 \pm 0.03^{\mathrm{d}}$ & $1.81 \pm 0.03^{\mathrm{d}}$ & $1.54 \pm 0.03^{\mathrm{c}}$ \\
$\begin{array}{c}\text { Total intensity } \\
(\text { mean } \pm \text { SEM) }(0-3)\end{array}$ & $0.72 \pm 0.04^{\mathrm{c}}$ & $1.11 \pm 0.05^{\mathrm{d}}$ & $0.60 \pm 0.04^{\mathrm{c}}$ & $0.23 \pm 0.03^{\mathrm{e}}$ \\
\hline
\end{tabular}

Means with different superscripts for each parameter are significantly different from each other $(P<0.01)$, Tukey's HSD test. $\mathrm{TH}$ : tip of the horn; $\mathrm{MH}$ : middle of the horn; $\mathrm{BH}$ : base of the horn; UB: uterine body.

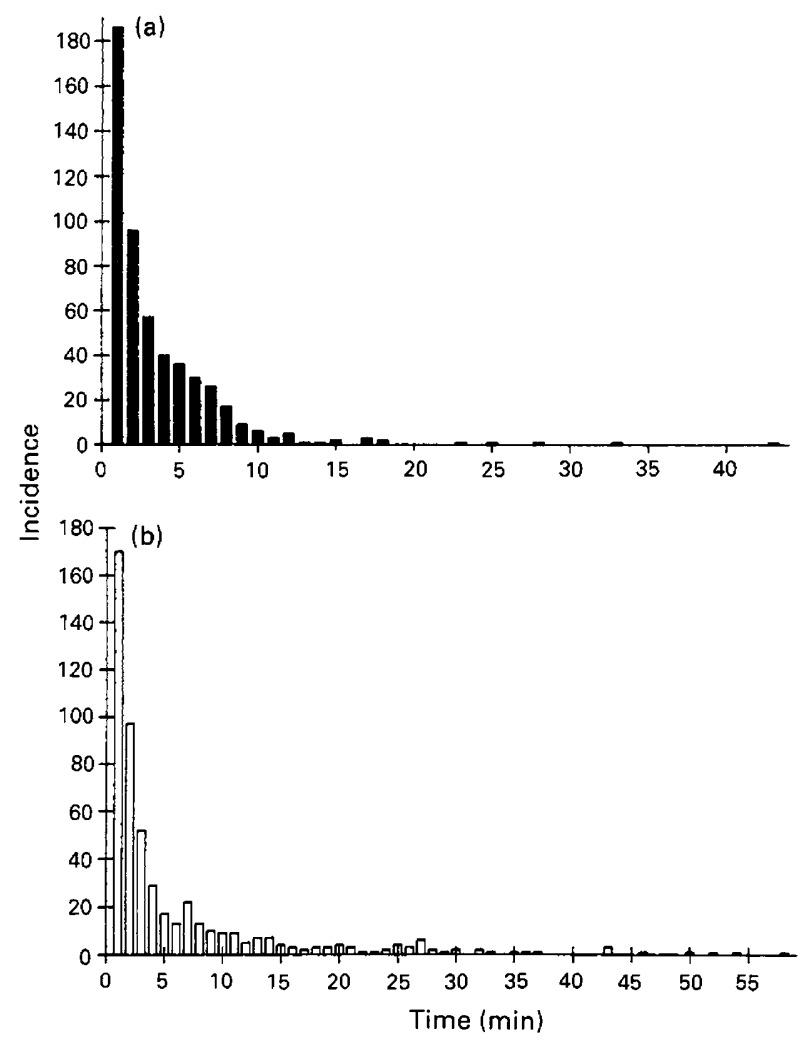

Fig. 5. The incidence of various durations of uterine electrical activity bursts in mares during (a) oestrus and (b) dioestrus. Activity bursts lasting 5 min or more were more common during dioestrus.

short durations of activity bursts dominated in both oestrus and dioestrus, activity bursts lasting more than 5 min were more common during dioestrus (Fig. 5). The mean duration of uterine activity bursts during dioestrus was $5.7 \pm 0.39 \mathrm{~min}$ compared with $3.32 \pm 0.18 \mathrm{~min}$ for mares at oestrus (Table 2).
Duration of activity bursts during dioestrus demonstrated more variability than during oestrus as determined by the standard deviation (SD for oestrus $=3.02$; SD for dioestrus $=8.20$ ).

Intensity. The degree of intensity of uterine electrical activity recorded depended on the stage of the oestrous cycle. Bursts of activity had a higher intensity during oestrus than during dioestrus $(P<0.005)$ (Table 2$)$. However, if periods of no activity were also included in the calculation (total intensity), the situation was reversed (Table 2). Mares in dioestrus had a significantly higher total intensity of uterine activity than did oestrous mares $(P<0.005)$. This was probably the result of the higher total time of uterine activity during dioestrus $(42.2 \%$ compared with $23.6 \%$ during oestrus; $P<0.005)$.

Synchronization. Synchronization of uterine electrical activity among different sites of the uterus demonstrated differences with regard to stage of the cycle. Synchronization was. more marked during oestrus than during dioestrus $(P<0.005)$. Complete synchrony was observed $66.85 \%$ of the time during oestrus compared with $37.7 \%$ of the time during dioestrus (Fig. 6). During both oestrus and dioestrus, uterine electrical activity was more synchronized than could be expected from calculation of random activity at different parts of the uterus $(12.5 \%$ synchronization).

\section{Discussion}

Electromyography measures electrical changes in the membrane potential of the myometrium. Although several investigators have questioned the accuracy of using EMG recordings of electrical activity to monitor myometrial contractility (Wolfs et al., 1971; Zerobin and Spörri, 1972; Rousseau and Prud'homme, 1974), Toutaine et al. (1983), demonstrated a close relationship 
Table 2. Myometrial electrical activity during oestrus and dioestrus in mares

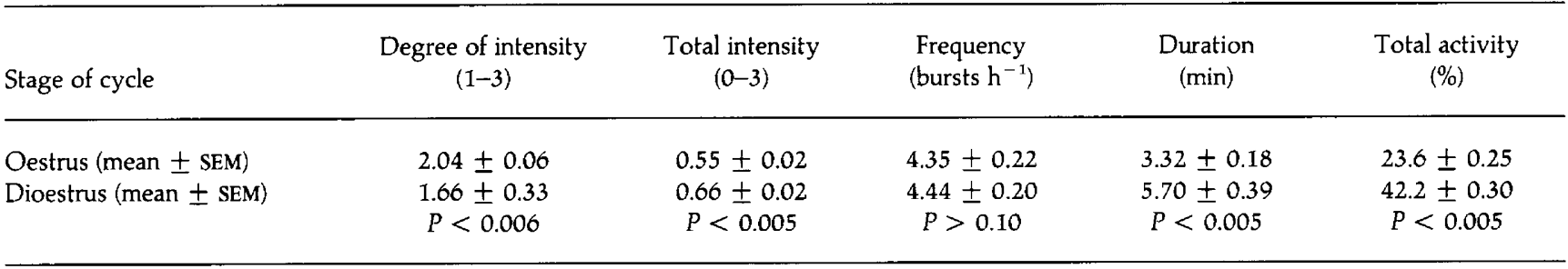

Intensity: 0: quiescence; I: low; 2 : intermediate; 3 : high.

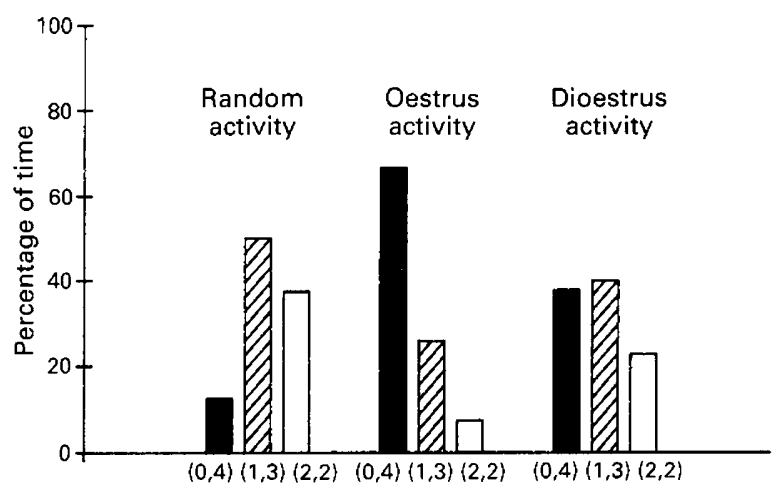

Fig. 6. Synchronization of myometrial electrical activity between four different sites of the uterus (tip of the left horn, middle of the left horn, base of the left horn and the uterine body). $(0,4)=$ complete synchronization with activity or quiescence at all recorded uterine locations; $(1,3)=$ intermediate synchronization with activity or quiescence simultaneous at three of the four recorded uterine locations; $(2,2)=$ asynchronization with activity at two sites and quiescence at two recorded sites. Random activity was calculated from the probability of a random event. The highest synchronization is seen at oestrus but dioestrus is more synchronized than is random activity.

between electrical and mechanical activity in uterine smooth muscle. In the present study, the term electrical myometrial activity, rather than uterine contractions, was used to describe the recorded EMG activity. The electrical activity was classified on the basis of intensity and frequency of electrical activity bursts. The amplitude of registrations was not analysed because complete standardization of the distances of impedances of electrodes in the uterus was not possible. The amplitude of EMG registrations depends upon the number of active muscle cells in the range of the recording electrodes.

In the present study, comparisons of electrical uterine activity at different sites of the uterus was possible because multiple pairs of electrodes were used. The intensity of uterine activity was selected as a parameter to investigate whether recordings from one site of the uterus are characteristic of the entire organ. Both the degree of intensity during bursts of activity and the mean of the total intensity during the entire recording time were greater in the middle and base of the uterine horn and middle of the horn, respectively, during dioestrus. The total intensity of activity was also greatest in the middle of the uterine horn during oestrus. Since total intensity of myometrial electrical activity includes periods of quiescence, these findings also reflect the duration of frequency by which the electrical activity occurs. These differences suggest that multiple site EMG analysis is preferred over single site EMG for a more complete picture of myometrial electrical activity. If maximal electrical activity is to be measured, electrodes should be implanted in the middle of the uterine horn.

The stage of the oestrous cycle was found to affect uterine activity. These results support the findings by Taverne et al. (1979b) and a recent report by Jones et al. (1991), but differ from those of others. The use of different techniques may explain the discrepancies between the studies. Goddard et al. (1985) and Ko et al. (1989) measured intrauterine pressure in mares and could not detect differences in uterine activity during the oestrous cycle. The present study showed that during oestrus, activity bursts were of greater intensity and shorter duration than during dioestrus. The dioestrous bursts of activity were variable, often diffuse and sometimes difficult to separate from each other with few periods of quiescence. Interestingly, there were no differences in the frequency of activity bursts between recordings during oestrus and dioestrus. The significantly higher total activity that was observed during dioestrus appeared, therefore, to be the result of the prolonged duration of activity bursts at this stage of the oestrous cycle. This finding correlates well with the increased uterine tone and tubularity that is characteristic of the uterus at dioestrus upon rectal palpation.

The physiological basis for the differences in myometrial activity during oestrus and dioestrus is not completely understood. A direct effect of oestrogens on the $\mathrm{Na}^{+}-\mathrm{K}^{+}$pump (Rossier et al., 1987) and the permeability of smooth muscle membrane to potassium have been demonstrated (Parkington and Coleman, 1990). These findings were, however, contradictory to observations made during pregnancy by Kuriyama and Suzuki (1976) and Yoshinaga et al. (1969).

An indirect regulation of myometrial activity by oestrogen and progesterone, through their effect on oxytocin and prostaglandins, is well documented. Oestrogen has been shown to increase the concentration of oxytocin receptors and to stimulate endometrial prostaglandin synthesis, whereas progesterone has the opposite effect (Demers et al., 1974; Roberts et al., 1976; Fuchs et al., 1983; Soloff et al., 1983; Schats et al., 1985; Schats et al., 1987). A 'progesterone block' of myometrial activity (Csapo, 1962) is believed to be due to both the negative effect of progesterone on oxytocin and prostaglandin receptors and to its inhibition of myometrial formation of gap junctions (Garfield et al., 1977, 1980, 1982; McKenzie and Garfield, 1985; Burghardt et al., 1987). The findings that synchronization of electrical activity in the uterus significantly increased from 
dioestrus to oestrus suggest a hormone dependent mechanism for the regulation of cell communication during oestrus in horses. As Taverne et al. (1979b) found changes in uterine electrical activity associated with plasma concentrations of progesterone, but not of oestrogen, it is likely that progesterone modulates myometrial activity and that a 'progesterone block' of mechanisms that are responsible for cell communication occurs in the horse. A wave of synchronized uterine activity during oestrus may be important for the transport of sperm cells into the oviduct and for the removal of uterine secretions and products, including dead sperm cells and seminal plasma, at the time of mating. Further studies are required to determine whether gap junctions or intermediate junctions (Thelander, 1989) are the source of cell communication during the oestrous cycle of horses.

This study established an objective method for analysing EMG recordings of myometrial electrical activity. Previous reports on myometrial EMG in mares have been based on visual interpretation of the data which complicates the comparison between experiments by different researchers. The present study also showed that a standardized procedure of EMG recordings of myometrial electrical activity should include a minimum recording time to allow meaningful statistical analyses.

It was concluded that electrical activity of the uterus changes with the stage of the oestrous cycle and differs between different parts of the uterus. Uterine electrical activity during oestrus was characterized by short, distinct bursts of activity with high intensity and marked synchronization. During dioestrus, uterine activity showed more diffuse bursts of activity, with longer duration, lower intensity and less synchronization than during oestrus.

This project was supported by the Equine Research Laboratory, University of California, Davis, with funds provided by Oak Tree Racing Association, the State of California satellite wagering fund and contributions by private donors. We would also like to acknowledge the financial support of the Swedish Racing Board (ATG). We thank C. Munro for performing hormonal analyses, G. Haluska for his insights and for providing us with electrodes and $\mathrm{T}$. Holliday for his insight and help with the manuscript. The technical assistance of M. Jorge deMoraes, C. Troedsson and C. Williams is gratefully acknowledged.

\section{References}

Burghardt RC, Gaddy-Kurten D, Burghardt RL, Kurten RC and Mitchell PA (1987) Gap junction modulation in rat uterus III. Structure-activity relationships of estrogen receptor binding ligands on myometrial and serosal cells Biology of Reproduction 36 741-751

Csapo AI (1962) Smooth muscle as a contractile unit Physiological Reviews 42 (Supplement 5) 7-33

Demers IM, Yoshuga K and Greep RO (1974) Prostaglandin F in monkey uterine fluid during the menstrual cycle and following steroid treatment Prostaglandins 5 513-520

Faltsi A and Brikas P (1990) An electromyographic study of uterine activity during normal and progesterone-regulated estrus in the ewe Theriogenology 34 603-611

Fuchs AR, Periyasamy S, Alexandrova M and Soloff MS (1983) Correlation between oxytocin receptor concentration and responsiveness to oxytocin in pregnant rat myometrium. Effect of ovarian steroids Endocrinology 113 $742-749$
Garfield RE, Sims SM and Daniel EE (1977) Gap junctions: their presence and necessity in myometrium during parturition Science 198 958-960

Garfield RE, Kannan MS and Daniel EE (1980) Gap junction formation in the myometrium: control by estrogens, progesterone and prostaglandins American Journal of Physiology 238 C $81-C 89$

Garfield RE, Puri CP and Csapo AI (1982) Endocrine, structural and functional changes in the uterus during premature labor American Journal of Obstetrics and Gynecology 142 21-27

Goddard PJ, Allen WE and Gerring EL (1985) Genital tract pressure in mares. I. Normal pressure and the effect of physiological events Theriogenology 23 815-827

Haluska GJ, Lowe JE and Currie WB (1987) Electromyographic properties of the myometrium correlated with endocrinology of the pre-partum and postpartum periods and parturition in pony mares Journal of Reproduction and Fertility Supplement 35 553-564

Jones DM, Fielden ED and Carr DH (1991) Some physiological and pharmacological factors affecting uterine motility as measured by electromyography in the mare Journal of Reproduction and Fertility Supplement 44 357-368

Ko JCH, Lock TF, Davis JL and Smith RP (1989) Spontaneous and oxytocininduced uterine motility in cyclic and postpartum mares Theriogenology 32 643-651

Krishnamurti CR, Kitts DD, Kitts WD and Tompkins JG (1982) Myoelectrical changes in the uterus of the sheep around parturition Joumal of Reproduction and Fertility $6459-67$

Kuriyama H and Suzuki H (1976) Changes in electrical properties of rat myometrium during gestation and following hormonal treatments Journal of Physiology 260 315-333

McKenzie LW and Garfield RE (1985) Hormonal control of gap junctions in the myometrium American Journal of Physiology 248 C296-C308

Munro C and Stabenfeldt G (1984) Development of a microtitre plate enzyme immunoassay for the determination of progesterone Joumal of Endocrinology $10141-49$

Naaktgeboren C, van der Weyden GC, Klopper PJ, Kroon CH, Schoof AG and Taverne MAM (1973) Electrophysiological observations of uterine motility during the oestrous cycle in sheep Journal of Reproduction and Fertility 35 511-518

Parkington HC and Coleman HA (1990) The role of membrane potential in the control of uterine motility. In Uterine Function, Molecular and Cellular Aspects pp 195-248 Ed. ME Carsten and JD Miller. Plenum Press, New York

Roberts JS, McCracken JA, Gavagan JE and Soloff MS (1976) Oxytocinstimulated release of prostaglandin $F_{2 a}$ from ovine endometrium in vitro: correlation with estrus cycle and oxytocin-receptor binding Endocrinology 99 1109-1114

Rossier BC, Geering K and Kraehenbuhl JP (1987) Regulation of the sodium pump: how and why? Trends in Biochemical Science 12 483-487

Rousseau JP and Prud'homme MJ (1974) Etude electromyographique de la motricité de l'uterus chez brebis. Action des hormones Annales de Biologique Animale Biochimie Biophysique 14 67-85

Ruckebush Y and Bayard F (1975) Motility of the oviduct and uterus of the cow during the oestrous cycle Journal of Reproduction and Fertility 43 23-32

Schats F, Markiewicz L, Barg P and Gurpide E (1985) In vitro effect of ovarian steroids on prostaglandin output by human endometrium and endometrial epithelial cells Journal of Clinical Endocrinology and Metabolism 61 361-367

Schats F, Markiewicz L and Gurpide E (1987) Differential effects of estradiol, arachidonic acid and A-23187 on prostaglandin $\mathrm{F}_{2 \alpha}$ output by epithelial and stromal cells of human endometrium Endocrinology 120 1465-1471

Soloff MS, Fernström MA, Periyasamy S, Soloff S, Baldwin S and Wieder M (1983) Regulation of oxytocin receptor concentration in rat uterine explants by estrogen and progesterone Canadian Joumal of Biochemistry and Cell Biology $61625-630$

Taverne MAM, Naaktgeboren C, Elsaesser F, Forsling ML, van der Weyden GC, Ellendorff F and Smidt D (1979a) Myometrial electrical activity and plasma concentrations of progesterone, estrogen and oxytocin during late pregnancy and parturition in the miniature pig Biology of Reproduction 21 1125-1134

Taverne MAM, van der Weyden GC, Fontijne P, Dielman SJ, Pashen RL and Allen WR (1979b) In-vivo myometrial electrical activity in the cycling mare Journal of Reproduction and Fertility 56 521-532

Thelander G (1989) Studies on the porcine myometrium during the oestrous cycle, pregnancy and parturition. $\mathrm{PhD}$ thesis, Faculty of Veterinary Medicine, Swedish University of Agricultural Science, Uppsala 
Thorburn GD, Harding R, Jenkin G, Parkington H and Sigger JN (1984) Control of uterine activity in the sheep Journal of Developmental Physiology 6 31-43

Toutaine PL, Garcia-Villar R, Hanzen C and Ruckebush Y (1983) Electrical and mechanical activity of the cervix in the ewe during pregnancy and parturition Journal of Reproduction and Fertility 68 195-204

Wolfs G, van Leeuwen M, Rottinghuis H and Boeles JT (1971) An electromyographic study of the human uterus during labor Obstetrics and Gynecology $37241-246$
Yoshinaga K, Hawkins RA and Stocker JF (1969) Estrogen secretion by the rat ovary in vivo during the estrous cycle and pregnancy Endocrinology 85 103-112

Zerobin K and Spörri H (1972) Motility of the bovine and porcine uterus and fallopian tube Advances in Veterinary Science and Comparative Medicine 16 303-354 